\title{
Clinical features of NK/T-cell EBV-associated LPD manifested as gastrointestinal symptoms in patients with normal immunity: a case report and literature review
}

\author{
Si-Zhu Wang ${ }^{1,2 \dagger}$, Ying-Huan Dai ${ }^{3 \dagger}$, Jie Zhang ${ }^{1,2^{*}}$ (⿺辶) Fang-Gen Lu ${ }^{1,2}$, La-Mei Yan ${ }^{1,2}$ and Shan $\mathrm{Wu}^{1,2}$
}

\begin{abstract}
Background: Epstein-Barr virus (EBV)-associated NK/T-cell lymphoproliferative disorder (LPD) involving the gastrointestinal tract is rarely observed in individuals with normal immunity. The atypical clinical, colonoscopic manifestations often confuse clinicians, leading to misdiagnosis and delays in the treatment.

Case presentation: Herein, we reported on a single case of a patient with gastrointestinal symptoms. Several colonoscopies showed multiple irregular ulcerations, while biopsies showed colitis with infiltration of neutrophils or lymphocytes. After 2 months follow-up, the patient was diagnosed with the extranodal NK/T-cell lymphoma, nasal type, and was treated with thalidomide. Later on, a second check was performed on his first pathological sample. Immunohistochemistry revealed EBV associated NK/T-cell LPD.

Conclusions: Multiple, multiform, and segmental gastrointestinal ulcers should be an indication for EBV infection, regardless of the presence of fever, lymphadenopathy, and hepatosplenomegaly. If EBV-associated NK/T-cell LPD is considered, serum EBV-DNA should be measured, and the tissue obtained by biopsy should be carefully analyzed for a positive expression of the EBER marker.
\end{abstract}

Keywords: Epstein-Barr virus, NK/T-cell lymphoproliferative disease, Intestine, Diagnosis, Immunocompetent

\section{Background}

EBV-associated NK/T-cell LPD is a new category adopted by the World Health Organization (WHO) in 2008. Its features include an excessive lymphoid proliferation of $\mathrm{T}$ or NK cells [1]. It is different from simple proliferative diseases (such as infection mononucleosis) and typical neoplastic diseases (such as NK/T cell lymphoma). The diagnosis is mainly based on pathological results. It usually occurs in children and young adults and is more likely

*Correspondence: jiezhang@csu.edu.cn

tSi-Zhu Wang and Ying-Huan Dai contributed equally to this work

${ }^{1}$ Department of Gastroenterology, The Second Xiangya Hospital,

Changsha 410011, Hunan, China

Full list of author information is available at the end of the article to develop in immunocompromised patients [2]. Gastrointestinal involvement in patients with normal immunity is very rare and the manifestations are not typical $[3,4]$.

Currently, there is limited available literature on this matter that is mostly based on sporadic case reports, most of which were misdiagnosed $[3,5,6]$. This disease shows a fulminant clinical course with poor prognosis, and relying solely on mucosal biopsy for diagnosis is not sufficient. Previous studies reporting on this disease have mainly focused on its pathology rather than clinical features. Nonetheless, reducing the rate of misdiagnosis and performing a more accurate and early diagnosis still remain as challenging issues. 
The purpose of this report is to present a case of EBV associated NK/T-cell LPD, which manifested with gastrointestinal symptoms and multiple irregular ulcerations.

\section{Case presentation}

A 30-year-old Chinese man was admitted to the gastroenterology department at Second Xiangya Hospital. He complained of having intermittent fever, diarrhea for five years, and haematochezia for over 20 days (May 2016). The highest temperature was $41^{\circ} \mathrm{C}$. No obvious abnormal results were found during physical examination. The liver function test and renal function test were normal. Results of serologic tests for ENA, vasculitis, ANA, and ANCA were all negative. A T-SPOT test yielded negative results. GM test, G-test, HIV, TP, and serum virus laboratory tests (CMV-IgM, CMV-IgG,
EBV-IgM, EBV-IgG) also showed negative results. Serum EBV-DNA was within the normal range. CT showed thickening of the transverse colon, descending colon, and the sigmoid wall (Fig. 1a-c). Several colonoscopies showed multiple irregular ulcerations in the terminal ileum and transverse colon, with segmental and longitudinal distribution (Fig. 1d-f). Several colonoscopic biopsies showed colitis with infiltration of neutrophils or lymphocytes in the lamina propria and formation of fissuring ulcers. The possibility of Crohn's disease (CD) was considered. The patient was treated with antibiotics, ethyl-prednisolone, thalidomide and mesalazine. However, the symptoms were not relieved.

After 2 months, a neoplasm was found in the nasal cavity, after which a biopsy was performed. Histological examinations showed atypical lymphocyte hyperplasia
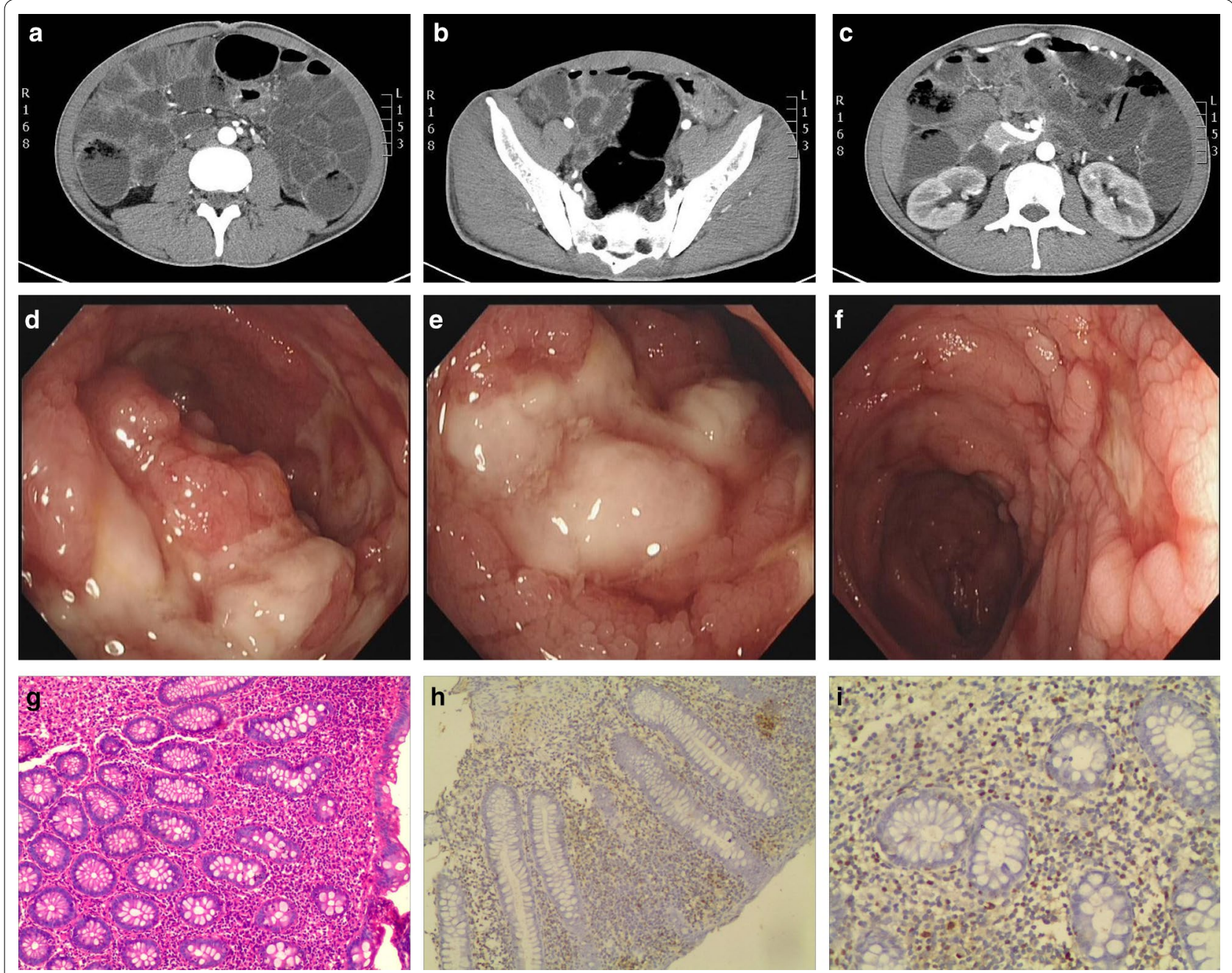

Fig. 1 Wall thickness and enhancement after a contrast-enhanced scan in transverse colon (a), descending colon (b) and sigmoid (c). Segmental irregular and longitudinal ulcerations in the terminal ileum (d, e). Multiple irregular ulcerations in transverse colon (f). HE stain in $\times 100$ magnification $(\mathbf{g})$. EBER expression in $\times 100$ magnification $(\mathbf{h})$. EBER expression in $\times 200$ magnification (i) 
with patchy necrosis and the destruction of some glandular structures. Immunohistochemistry result was CD3 $(+), \mathrm{CD} 2(++), \mathrm{CD} 20(-), \mathrm{CD} 79 \alpha(-), \mathrm{CD} 56(+), \mathrm{TiA}-1$ $(+)$, CD21 (-), mum-1 (+), CD5 (-), CyclinD1 (-), TdT $(-)$ and Ki-67 $(80 \%+)$. The EBER in situ hybridization was $>100 / \mathrm{HPF}$. The patient was diagnosed as extranodal NK/T-cell lymphoma, nasal type. Considering that his family members rejected chemotherapy, he was treated with thalidomide (50 mg Qn). The patient was followed for two years until 2018 and, currently (July 07, 2020), is still alive.

After he was diagnosed as extranodal NK/T-cell lymphoma, nasal type, we took in consideration the possibility of misdiagnosis. The first pathologic result was rechecked. Formation of multiple ulcers was discovered, accompanied by lymphocytes and plasmocytes infiltration in the mucous. Reduced glands, lymphocytic infiltration, and atypical lymphocytes were also observed. Immunohistochemistry result was CK (epithelium+), CD3 (10\%+), CD4 (40\%), CD20 (10\%+), CD21 (-), Ki-67 $(30 \%+)$, EBER in situ hybridization suggested 40/HPF (Fig. 1g-i). Therefore, the patient was suffering from EBV associated NK/T-cell LPD in the beginning.

\section{Discussion and conclusions}

Herein, we reported a single case of a patient with EBV + NK/T-cell LPD who manifested chronic gastrointestinal symptoms. No sign of lymphoproliferative disorder was found in repeated colonoscopies. Therefore, the patient was treated for $\mathrm{CD}$. Consequently, a neoplasm in the nasal cavity was found, and the patient was diagnosed with lymphoma. However, after the second analysis of a biopsy, the initial diagnosis was corrected to $\mathrm{EBV}+\mathrm{NK} / \mathrm{T}$-cell LPD.

EBV + LPD is usually observed in patients with immune deficiencies [7]. However, some rare cases may manifest gastrointestinal symptoms [3]. The intestinal LPDs are the most frequent form of extranodal LPD with clinical presentation that is similar to that of IBD [8]. Therefore, in most cases misdiagnosis is commonly identified only after being mistreated or their condition deteriorates.

In the present study, we searched PubMed and CNKI for relevant literature published until May 2019 using the following keywords: 'lymphoproliferative disease' and 'intestine' and 'EBV.' Only studies or case reports involving patients over 12 years old with normal immunity and T/NK cell lineage derived were found. Their initial symptoms were gastrointestinal symptoms, and the immunity was normal. In total, 24 patients were reported whose clinical features are summarized in Table 1 [3-7, 9-13].
Patients with EBV+T/NK-LPD and gastrointestinal symptoms, were mainly younger male individuals, which is consistent with the characteristics found in our case study. In addition, all patients were Asians, which suggests genetic susceptibility [2]. The most common clinical manifestation in patients with EBV + T/NK-LPD was fever (the temperature ranged from 37 to $41{ }^{\circ} \mathrm{C}$ ) [1]. However, not all the patients had a fever; some patients developed fever after applying hormonal or anti-TNF [6]. Besides fever, diarrhea, abdominal pain, and hematochezia were also observed. In patients with chronic active EBV infective enteritis, diarrhea and abdominal pain were the most common gastrointestinal symptoms, along with fever, which was intermittent and mostly over $39^{\circ} \mathrm{C}$ [17]. Briefly, the clinical manifestations of EBV $+\mathrm{T} /$ NK LPD, which manifested as gastrointestinal symptoms are atypical. Therefore, most patients were misdiagnosed with $\mathrm{CD}$, infection, and so on $[3,6,7]$.

As for laboratory inspection, the most common blood routine results were mild leukocytosis and anemia [4, 9-11]. Anemia was common in EBV + T/NK LPD [1], but it was still not specific due to its similarity to a CD. Liver function showed hypoalbuminemia [3, 4, 9-11], while transaminase elevation was rarely observed [3]. Bilirubin and coagulation function were also normal in the majority of EBV $+\mathrm{T} / \mathrm{NK}$ LPD cases. However, liver dysfunction was observed in $77 \% \mathrm{EBV}+\mathrm{T} / \mathrm{NK} \mathrm{LPD}$ patients [11]; which may be related to the different initial infiltrating positions. Deep lymphadenopathy in $\mathrm{CT}$ was also commonly reported $[3,4,6,10,11]$; however, superficial lymphadenopathy and hepatosplenomegaly were rare [4]. According to Kimura et al. [1], hepatomegaly and lymphadenopathy are common in patients with EBVassociated T/NK-lymphoproliferative cell diseases. These symptoms are also commonly found in chronic active Epstein-Barr virus infective enteritis [17]. Briefly, deep lymphadenopathy may provide some general clue, which led to conclusion that lymphadenopathy and hepatosplenomegaly may happen in the late stage of the disease.

In terms of colonoscopy examination, multiple and multi-shaped ulcers, which were commonly found, were distributed in the gastrointestinal tract $[5-7,9]$. No obvious segmental feature was noticed. Ulcers vary in shape, depth, and size $[3,5,7]$. Similar ulcers were also observed in patients with chronic active EBV infective enteritis [17]. Those ulcers lack of typical features of $\mathrm{CD}$ (Crohn's disease) or ITB(Intestinal tuberculosis), like longitudinal or transverse ulcers, and cobblestone appearance [18]. Yet, there is still some other non-typical behavior in colonoscopies, such as diffusely atrophic small-intestinal villi and erythema $[4,12]$. As for CT examination, segmental wall thickening was common $[6,11]$, which was similar to $\mathrm{CD}$ and ITB. 


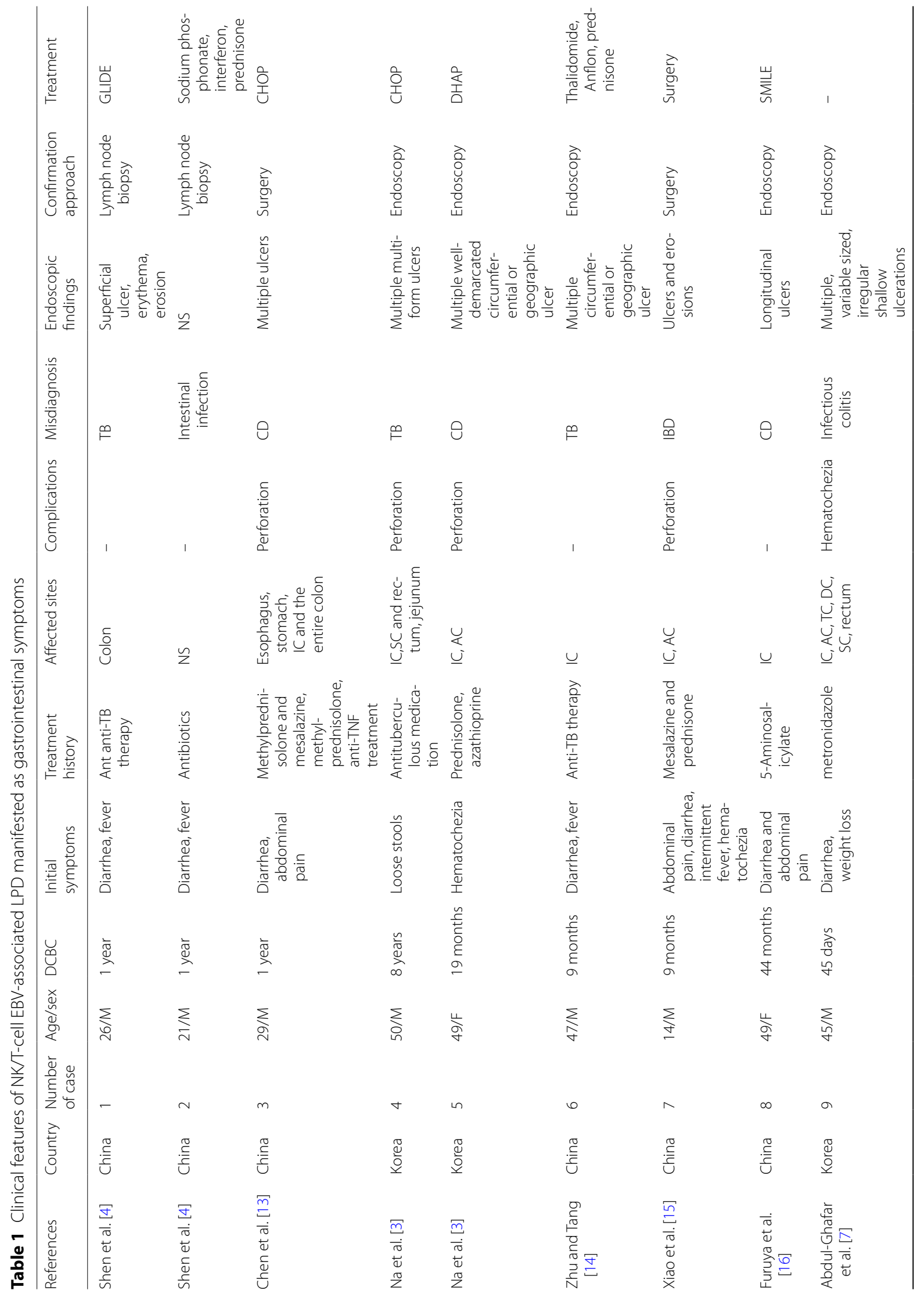




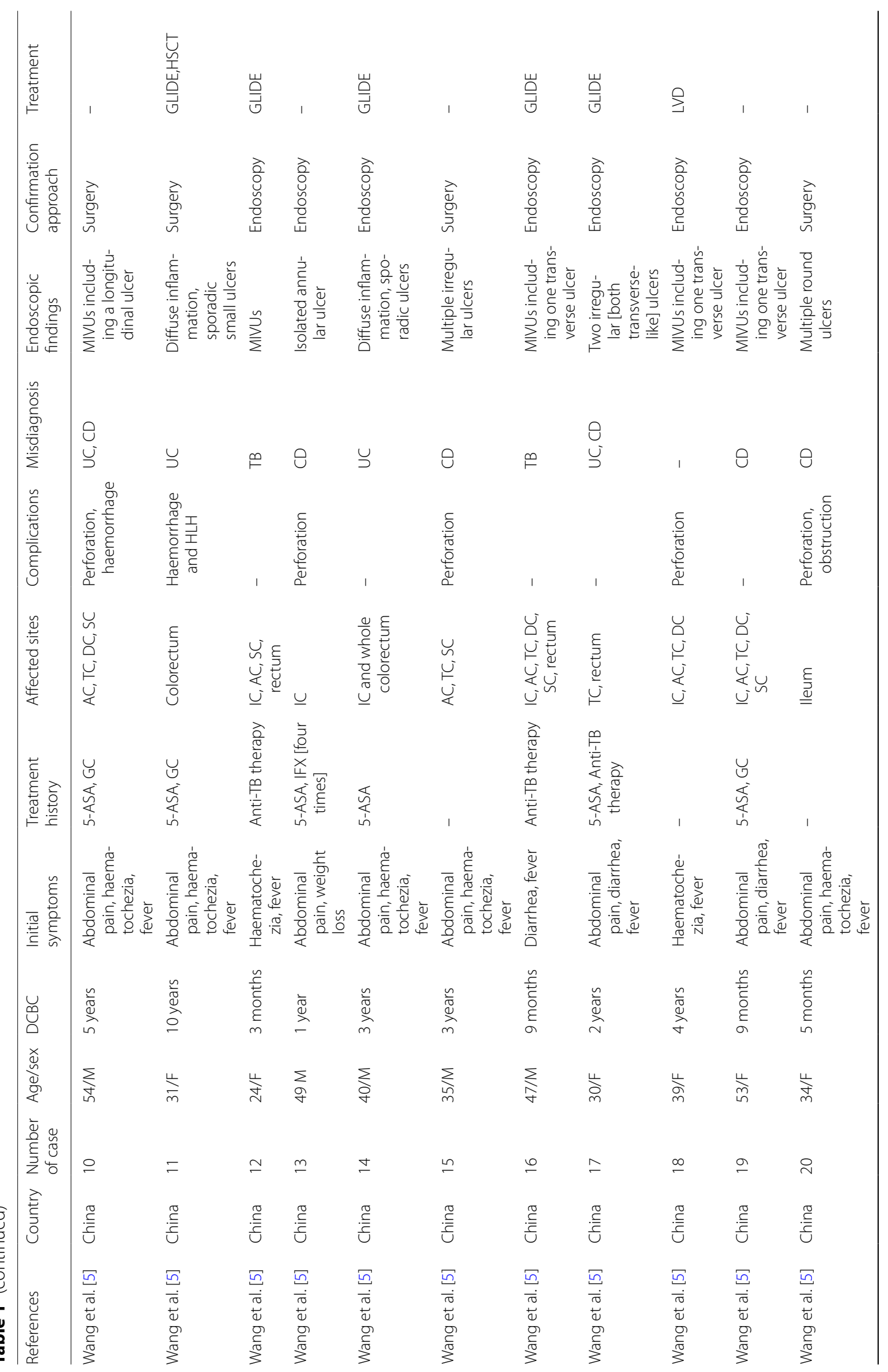




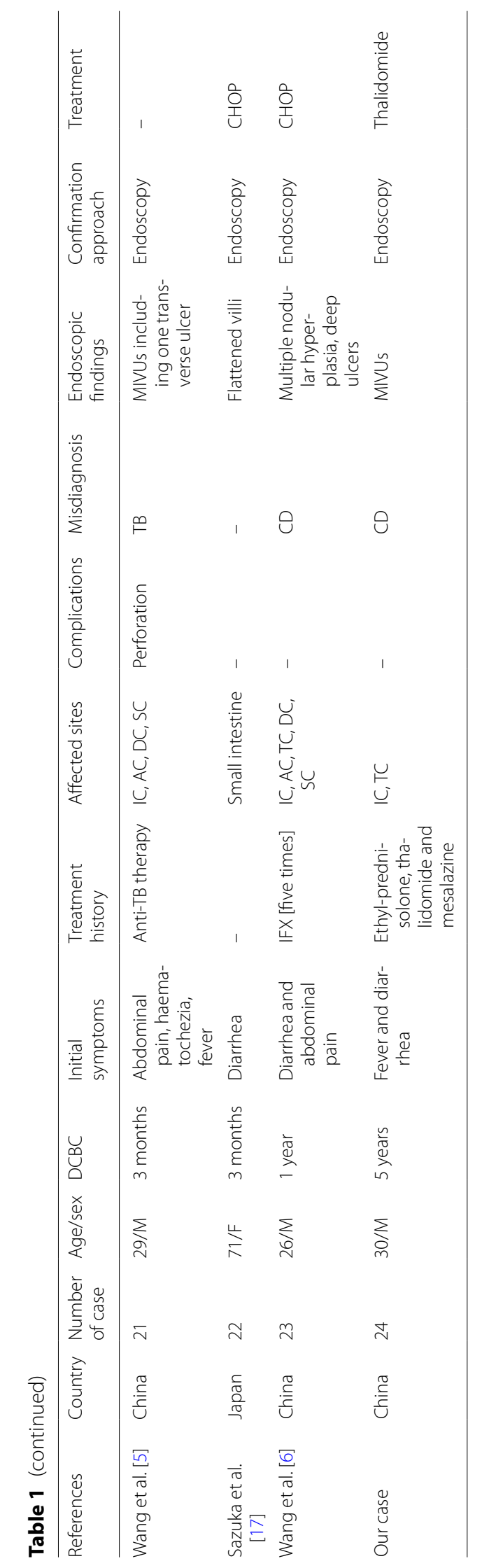


EBV has an etiological role in various diseases, including infectious mononucleosis, chronic active EBV infection, and malignancies such as nasopharyngeal cancer and Burkitt's lymphoma [19]. Serological studies of EBV infection include EBV antibody and EBV-DNA. Because the EBV infects $>90 \%$ of humans and persists during their lifetime, most people develop an EBV antibody [19]. Nevertheless, some patients may lack serum EBV-DNA duplication but be positive for EBER. In our case, the patient was negative for EBV-DNA but positive for EBER. EBER in situ hybridization suggested the presence of EBV-infected cells in the tissues. We assumed that EBV occurred only in intestinal tissue at an early stage of the disease. The detection of EBER seems to be more significant. EBER showing over 50/HP is considered meaningful generally. However, we found that some results didn't conform to it, which may be related to the uneven EBV distribution in biopsy specimens. This in turn suggests that multiple and multifocal specimens are necessary when considering the possibility of EBV + disease.

Considering the indistinguishable clinical manifestations from other intestinal disorders, $\mathrm{EBV}+\mathrm{NK} / \mathrm{T}$ LPD is diagnosed based on pathology. Some patients developed lymphoma. A typical lymphocytic proliferation with varied sized lymphocytes is also important. In patients with EBV + NK/T-LPD, lymphocytes may infiltrate other sites, such as lymph node and vessel. As for immunohistochemistry, CD3, CD56, TIA-1, and EBER are commonly expressed; Ki-67 ranges from 5 to 80\% [4$6,11]$. In our cases, at the early stage of the disease, Ki-67 was $30 \%$ and then increased to $80 \%$, which indicated that Ki-67 might be associated with the disease progression. Moreover, Wang et al. [5] analyzed the pathological features of the biopsies in the early stage of EBV + NK/TLPD and found that these tissues were characterized by small- or medium-sized lymphoid cells, ALCs, LELs, and angiocentric infiltrations. EBER-positive cells can be detected by in situ hybridizations.

According to Kimura et al., in a median follow-up period of 46 months, almost half of EBV +NK/T-LPD died of severe organ complications. We found that some cases developed lymphoma $[1,5,6]$. Currently, there is still no standard treatment for EBV + NK/T-LPD. Patients with post-transplant lymphoproliferative disorders are usually treated with RIS (reduction of immune suppression) and other treatment modalities (chemotherapy, radiotherapy, or surgery). Yet, the response is still poor [20]. Sakai et al. has shown that interferon has a good effect on patients with chronic active Epstein-Barr virus infection [21]. Thalidomide is a potential therapeutic strategy for ENKTLassociated HPS [22]. In clinic, the main treatments include interferon, thalidomide to chemotherapy, and $\operatorname{HSCT}[3,5$,
6]. However, the overall death rate is still high. Therefore, new treatment modalities should be investigated.

EBV-associated NK/T LPD accompanied by gastrointestinal symptoms is rare in patients with normal immunity. These patients generally have a poor prognosis and a median survival of only a few months despite intensive chemotherapy [23]. Multiple, multiform, and segmental gastrointestinal ulcers should be an indication for EBV infection, regardless of the presence of fever, lymphadenopathy, and hepatosplenomegaly. If Epstein-Barr virusassociated NK/T-cell LPD is considered, serum EBV-DNA should be measured, and the tissue obtained by biopsy should be carefully analyzed for a positive expression of EBER marker.

\section{Abbreviations}

EBV: Epstein-Barr virus; LPD: Lymphoproliferative disorder; WHO: World Health Organization; CD: Crohn's disease.

\section{Acknowledgements}

Not applicable.

\section{Authors' contributions}

SW and JZ conceived the study; YD, SW and LY collected and interpreted the data; SW drafted the manuscript; JZ and FL critically reviewed the manuscript; YD, JZ and SW revised the manuscript. All authors read and approved the final manuscript.

\section{Funding}

Not applicable.

\section{Availability of data and materials}

All data generated or analysed during this study are included in this published article.

\section{Declarations}

Ethics approval and consent to participate

The study was approved by the institutional review board of Second Xiangya Hospital of Central South University.

\section{Consent for publication}

Written informed consent was obtained from the patient for publication of this case report and any accompanying images.

\section{Competing interests}

Not applicable.

\section{Author details \\ 1 Department of Gastroenterology, The Second Xiangya Hospital, Chang- sha 410011, Hunan, China. ${ }^{2}$ Research Center of Digestive Disease, Central South University, Changsha 410011, Hunan, China. ${ }^{3}$ Department of Pathology, The Second Xiangya Hospital of Central South University, Changsha 410000, Hunan, China.}

Received: 30 September 2020 Accepted: 11 March 2021

Published online: 10 June 2021

\section{References}

1. Kimura H, Ito Y, Kawabe S, Gotoh K, Takahashi Y, Kojima S, et al. EBV-associated T/NK-cell lymphoproliferative diseases in nonimmunocompromised hosts: prospective analysis of 108 cases. Blood. 2012;119(3):673-86. 
2. Ohshima K, Kimura H, Yoshino T, Kim CW, Ko YH, Lee SS, et al. Proposed categorization of pathological states of EBV-associated T/natural killer-cell lymphoproliferative disorder (LPD) in children and young adults: overlap with chronic active EBV infection and infantile fulminant EBV T-LPD. Pathol Int. 2008;58(4):209-17.

3. Na HK, Ye BD, Yang SK, Yang DH, Jung KW, Kim KJ, et al. EBV-associated lymphoproliferative disorders misdiagnosed as Crohn's disease. J Crohns Colitis. 2013;7(8):649-52.

4. Shen K, Chen XC, Liu T. An adult systemic Epstein-Barr virus positive T cell lymphoproliferative disease with intestinal lesions as the first manifestation. West Chin Med J. 2013;28(6):840-3.

5. Wang Z, Zhang W, Luo C, Zhu M, Zhen Y, Mu J, et al. Primary intestinal Epstein-Barr virus-associated natural killer/T-cell lymphoproliferative disorder: a disease mimicking inflammatory bowel disease. J Crohns Colitis. 2018;12(8):896-904.

6. Wang S, Dai Y, Zhang J, Ou D, Ouyang C, Lu F. Intestinal ulcers as an initial finding in EBV-associated lymphoproliferative disorder: a case report. Medicine (Baltimore). 2020;99(3):e18764

7. Abdul-Ghafar J, Kim JW, Park KH, Cho MY. Fulminant Epstein-Barr virusassociated T-cell lymphoproliferative disorder in an immunocompetent middle-aged man presenting with chronic diarrhea and gastrointestinal bleeding. J Korean Med Sci. 2011;26(8):1103-7.

8. Sokol H, Beaugerie L, Maynadie M, Laharie D, Dupas JL, Flourie B, et al. Excess primary intestinal lymphoproliferative disorders in patients with inflammatory bowel disease. Inflamm Bowel Dis. 2012;18(11):2063-71.

9. Cho EY, Kim KH, Kim WS, Yoo KH, Koo HH, Ko YH. The spectrum of Epstein-Barr virus-associated lymphoproliferative disease in Korea: incidence of disease entities by age groups. J Korean Med Sci. 2008;23(2):185-92.

10. Park S, Kim K, Kim WS, Yoo KH, Koo HH, Ko YH. Systemic EBV+ T-cell lymphoma in elderly patients: comparison with children and young adult patients. Virchows Arch. 2008;453(2):155-63.

11. Chang KL, Chen YY, Chen WG, Hayashi K, Bacchi C, Bacchi M, et al. EBNA-1 gene sequences in Brazilian and American patients with Hodgkin's disease. Blood. 1999;94(1):244-50.

12. Liu R, Wang M, Zhang L, Zhou W, Huang Y, Guo H, et al. The clinicopathologic features of chronic active Epstein-Barr virus infective enteritis. Mod Pathol. 2019;32(3):387-95.

13. Chen $H$, Zhang Y, Jiang Z, Zhou W, Cao Q. A case report of NK-cell lymphoproliferative disease with a wide involvement of digestive tract develop into Epstein-Barr virus associated NK/T cell lymphoma in an immunocompetent patient. Medicine (Baltimore). 2016;95(12):e3176.

14. Zhu X, Tang H. A case of intestinal T-cell lymphoproliferative disorders misdiagnosed as intestinal tuberculosis. Clin Misdiagnosis Mistherapy. 2017;30(6):14-17. https://doi.org/10.3969/j.issn.1002-3429.2017.06.006.

15. Xiao HJ, Li J, Song HM, Li ZH, Dong M, Zhou XG. Epstein-barr virus-positive t/nk-cell lymphoproliferative disorders manifested as gastrointestinal perforations and skin lesions: a case report. Medicine (Baltimore). 2016 Feb;95(5):e2676. https://doi.org/10.1097/MD.0000000000002676.

16. Furuya G, Abe H, Shinozaki-Ushiku A, Yamashita A, Ihara S, Hirata Y, Chiba A, Fujioka Y, Kurokawa M, Koike K, Fukayama M. Extranodal NK/T-cell lymphoma of the nasal cavity developed in a patient with intestinal Epstein-Barr virus-positive T/NK-cell lymphoproliferative disorder. Pathol Res Pract. 2018;214(7):1051-5. https://doi.org/10.1016/j.prp.2018.05.022.

17. Sazuka S, Takahashi Y, Kawaguchi T, Sato T, Nakagawa T, Furuya Y, et al. Endoscopic findings of small-intestinal Epstein-Barr virus-associated T-cell lymphoproliferative disorder. Endoscopy. 2012;44(Suppl 2 UCTN):E30-1.

18. Cohen Jl. Epstein-Barr virus infection. N Engl J Med. 2000;343(7):481-92.

19. Thorley-Lawson DA, Gross A. Persistence of the Epstein-Barr virus and the origins of associated lymphomas. N Engl J Med. 2004;350(13):1328-37.

20. Yoon SO, Yu E, Cho YM, Suh C, Kim KM, Han DJ, et al. Post-transplant lymphoproliferative disorders: clinicopathological analysis of 43 cases in a single center, 1990-2009. Clin Transpl. 2012;26(1):67-73.

21. Wen H, Ma H, Cai Q, Lin S, Lei X, He B, et al. Recurrent ECSIT mutation encoding $\mathrm{V} 140 \mathrm{~A}$ triggers hyperinflammation and promotes hemophagocytic syndrome in extranodal NKTT cell lymphoma. Nat Med. 2018;24(2):154-64.

22. Carbone A, Gloghini A, Dotti G. EBV-associated lymphoproliferative disorders: classification and treatment. Oncologist. 2008;13(5):577-85.

23. Rezk SA, Weiss LM. Epstein-Barr virus-associated lymphoproliferative disorders. Hum Pathol. 2007;38(9):1293-304.

\section{Publisher's Note}

Springer Nature remains neutral with regard to jurisdictional claims in published maps and institutional affiliations.
Ready to submit your research? Choose BMC and benefit from:

- fast, convenient online submission

- thorough peer review by experienced researchers in your field

- rapid publication on acceptance

- support for research data, including large and complex data types

- gold Open Access which fosters wider collaboration and increased citations

- maximum visibility for your research: over $100 \mathrm{M}$ website views per year

At BMC, research is always in progress.

Learn more biomedcentral.com/submissions 